\title{
An unusual cause of haematuria
}

\section{AM Abeygunasekera ${ }^{1}$, BL Perera ${ }^{2}$ and GG Jayawardena ${ }^{3}$}

(Index words: Plastic tube in the bladder, psychiatric referral)

The variety of foreign bodies inserted into the bladder defies belief, and includes a wide range of objects [1]. Self-insertion is done usually for eroticism, inquisitiveness or as a consequence of disturbed behaviour and lack of insight (e.g. psychiatric and senile states, under the influence of alcohol). Vesical foreign bodies are much commoner in males probably due to their use as a masturbatory aid.

A 32-year old man presented with lower abdominal pain and haematuria. The xray of the abdomen revealed a coiled tube in the area of the bladder (Figure 1). Initially he denied inserting a tube into the urethra, but later he accepted that he did. His wife is employed abroad. Cystoscopic examination confirmed the presence of a plastic tube inside the bladder and an attempt to retrieve it using the grasping forceps failed due to the stiffness of the material and the wide diameter of the tube. Using the stone punch it was possible to grasp the end of the tube and remove it completely. The length of the tube was $127 \mathrm{~cm}$ and the diameter $0.5 \mathrm{~cm}$ (Figure 2).

Clinical diagnosis of an intravesical foreign body is difficult as patients deny insertion [1]. Nearly all foreign bodies in the bladder can be detected by plain xray and ultrasonography. Management is aimed at providing

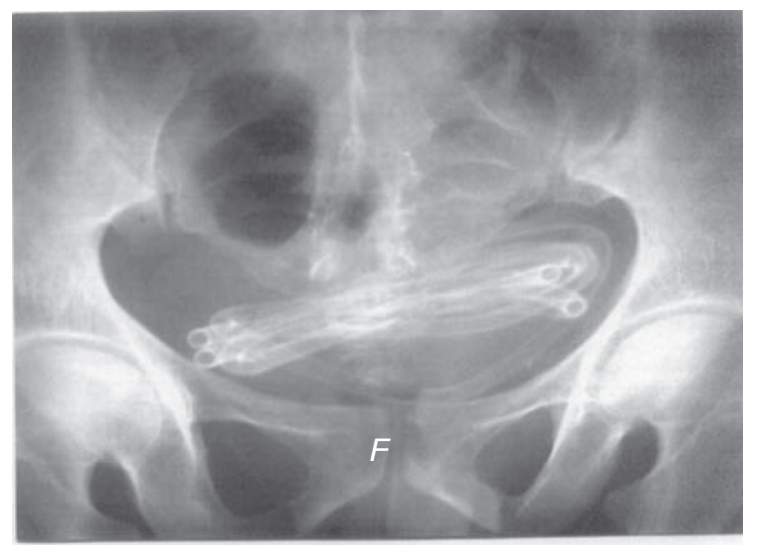

Figure 1. Xray of abdomen showing plastic tube in the bladder area.

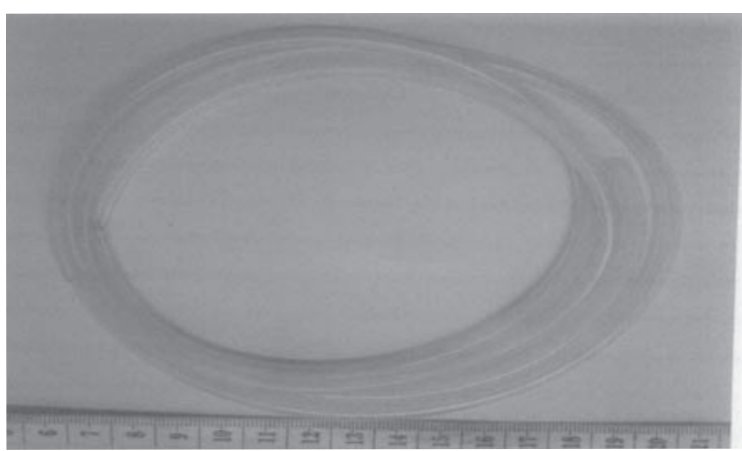

Figure 2. Tube after removal.

complete removal with minimal trauma to bladder and urethra. This should be followed by treatment of any identifiable psychological disorder [2]. Although most objects in the bladder can be removed with cystoscopic grasping forceps, that was not possible in this patient. The stone punch forceps was used successfully. When a coiled, long tube is removed, it is important to remember the possibility of knotting inside during the retrieval which could complicate the removal. A psychiatric examination in every case of self-inserted foreign body is controversial [3]. Most patients are psychologically normal, especially when the purpose of insertion is masturbatory.

\section{References}

1. van Ophoven A, deKernion JB. Clinical management of foreign bodies of the genitourinary tract. Journal of Urology 2000; 164: 274-87.

2. Osca JM, Broseta E, Server G, Ruiz JL, Gallego J, JimenezCruz JF. Unusual foreign bodies in the urethra and bladder. British Journal of Urology 1991; 68: 510-2.

3. Kenney RD. Adolescent males who insert genitourinary foreign bodies: is psychiatric referral required? Urology 1988; 23: 127-9.

${ }_{1}^{1}$ Urological Surgeon, ${ }^{2}$ General Surgeon, ${ }^{3}$ Psychiatrist, Karapitiya Teaching Hospital, Galle, Sri Lanka. Correspondence: Tel: +94 0112763427, e-mail: <amabey@sltnet.lk> (Competing interests: none declared). Received 22 July 2005 and accepted 26 July 2005. 